\title{
Buthionine Sulfoximine
}

National Cancer Institute

\section{Source}

National Cancer Institute. Buthionine Sulfoximine. NCI Thesaurus. Code C1029.

A synthetic amino acid. Buthionine sulfoximine irreversibly inhibits gamma-

glutamylcysteine synthase, thereby depleting cells of glutathione, a metabolite that plays a critical role in protecting cells against oxidative stress, and resulting in free radicalinduced apoptosis. Elevated g lutathione levels are associated with tumor cell resistance to alkylating agents and platinum compounds. By depleting cells of glutathione, this agent may enhance the in vitro and in vivo cytotoxicities of various chemotherapeutic agents in drug-resistant tumors. Buthionine sulfoximine may also exhibit antiang iog enesis activity. ( $\mathrm{NCl} 04)$ 